\title{
Post-operative left atrial volume index is a predictor of the occurrence of permanent atrial fibrillation after mitral valve surgery in patients who undergo mitral valve surgery
}

Min-Kyung Kang ${ }^{1}$, Boyoung Joung ${ }^{2}$, Chi Young Shim², In Jeong Cho², Woo-In Yang ${ }^{3}$, Jeonggeun Moon ${ }^{4}$, Yangsoo Jang ${ }^{2}$, Namsik Chung ${ }^{2}$, Byung-Chul Chang ${ }^{2}$ and Jong-Won Ha ${ }^{2 *}$

\begin{abstract}
Background: Atrial fibrillation (AF) can occur even after the correction of mitral valve (MV) pathology in patients who have pre-operative sinus rhythm and undergo MV surgery. However, the factors associated with the occurrence of AF after MV surgery are still unclear. The aim of this retrospective study was to investigate the factors determining the occurrence of permanent AF after MV surgery in patients with preoperative sinus rhythm who underwent MV surgery.

Methods: Four hundred and forty-two patients (mean age $46 \pm 12,190$ men) who underwent MV surgery and sinus rhythm were investigated retrospectively. Transthoracic echocardiography was performed before and after MV surgery at the time of dismissal.

Results: Permanent post-operative AF occurred in 81 (18\%) patients even after successful MV surgery and preoperative sinus rhythm. It was more common in rheumatic etiology, a presence of mitral stenosis, lower preand post-operative left ventricular ejection fraction, higher post-operative mean diastolic pressure gradient across mitral prosthesis, larger post-operative left atrial volume index (LAVI) and lesser degrees of reduction in LAVI after surgery. In multiple regression analysis, post-operative LAVI was found to be an independent predictor for occurrence of AF. Post-operative LAVI $>39 \mathrm{ml} / \mathrm{m} 2$ was the cut-off value for best prediction of new onset permanent AF (sensitivity: 79\%, AUC: 0.762, SE: 0.051, $p<0.001$ ).
\end{abstract}

Conclusion: New-onset permanent post-operative AF is not uncommon, even after successful MV surgery despite pre-operative sinus rhythm. Larger post-operative LAVI was an independent predictor for the occurrence of AF.

Keywords: Atrial fibrillation, Mitral valve, Left atrium

\section{Background}

Increased left atrial (LA) size is associated with the occurrence of atrial fibrillation (AF) [1]. Therefore, AF is frequently observed in patients with chronic mitral valve (MV) disease, which invariably induces LA remodeling [2-4]. On the other hand, reduction of LA size (reverse LA remodeling) can also occur after correction of MV

\footnotetext{
* Correspondence: jwha@yuhs.ac

${ }^{2}$ Division of Cardiology and Cardiovascular Surgery, Severance Cardiovascular Hospital, Yonsei University College of Medicine, 134 Shinchon-dong, Seodaemun-gu, Seoul 120-752, Republic of Korea

Full list of author information is available at the end of the article
}

pathology $[3,5]$. It has been shown that the degree of reverse LA remodeling varies, particularly according to pre-operative cardiac rhythm. Moreover, pre-operative sinus rhythm is associated with larger degrees of reverse LA remodeling [3]. In addition, this structural reversal can also induce reversal of electrophysiologic abnormalities that are predisposed to the occurrence of AF. Therefore, reversal of these changes by treatment, i.e., MV surgery, could potentially have important implications for the prevention of AF [5, 6]. Nevertheless AF can occur even after correction of MV pathology in patients who have undergone MV surgery [7-17]. However, the incidence and 
predictors of new onset permanent AF after MV surgery have not been clearly defined. Therefore, the aim of this study is to investigate the prevalence and predictors of the occurrence of new onset permanent $\mathrm{AF}$ in patients with MV diseases who have undergone MV surgery and sinus rhythm pre-operatively.

\section{Methods}

\section{Study design and participants}

A total of 1841 patients underwent MV surgery from June 1982 to February 2009. Among them, patients with preexisting AF, concomitant MAZE procedure during surgery $(n=1189)$, patients with permanent pacemaker implantation $(n=20)$, and patients unknown pre-operative rhythm $(n=190)$ were excluded. The remaining 442 patients (mean age $46 \pm 12,191$ men) comprised the study population (Fig. 1). We reviewed the medical records to define the etiology of MV pathology and reason for valve surgery in addition to pre- and post-operative transthoracic echocardiography (TTE) and electrocardiogram (ECG). ECG was taken pre- and post-operatively and at follow up once a year thereafter. New onset permanent AF was defined as the occurrence of AF post-operatively detected by postoperative ECG during the hospital stay and that persisted thereafter.

\section{Echocardiography}

TTE was performed by standard techniques with a 2.5$\mathrm{MHz}$ transducer. Two-dimensional echocardiographic images were obtained in the standard parasternal longaxis and apical 2 and 4 chamber views. Left ventricular (LV) ejection fraction (EF) was assessed by the modified Quinones method. Mediolateral (ML) and superior/inferior (SI) dimensions of LA were measured from the apical 4 chamber view, and anteroposterior (AP) dimensions were measured from the parasternal long axis view at the end-systole. Maximal LA volume was calculated using the prolate ellipsoid model 3 and indexed to the body surface area (LA volume index; LAVI). Measurement of LA volume was available in 200 of 442 patients at pre- and post-operative periods. In those patients, the LA volume change and the percentage of LA volume change were calculated [18]. Assessment of valvuar heart diseases were based on the guidelines [19].

\section{Statistical analysis}

Continuous variables are presented as means \pm standard deviation (SD) and compared using Student's unpaired $\mathrm{t}$ test or Mann-Whitney's U test. Categorical variables are presented as numbers or percentages, and used the Chisquare test. To determine the variables associated with the occurrence of AF, logistic regression analysis was performed separately using clinical variables and echocardiographic findings. The predictive ability of the LAVI was determined by the area under the receiver-operating characteristic curves (ROC). Kaplan-Meier estimator was used for AF free survival curves. $P$ value $<0.05$ was considered statistically significant.

\section{Results}

The enrolled patients were classified into the two groups according to the occurrence of permanent AF or maintained sinus rhythm after MV surgery (normal sinus rhythm [NSR] group vs. AF group). Post-operative new onset permanent AF occurred in 81 (18\%) patients. Baseline characteristics of the study subjects are shown in Table 1. The mean age at the time of surgery was similar in both groups. The majority of patients (81\%) had rheumatic etiology and others (19\%) had nonrheumatic etiology, such as infective endocarditis, MV prolapse, or chordae rupture. The proportion of rheumatic valve disease was significantly higher in patients

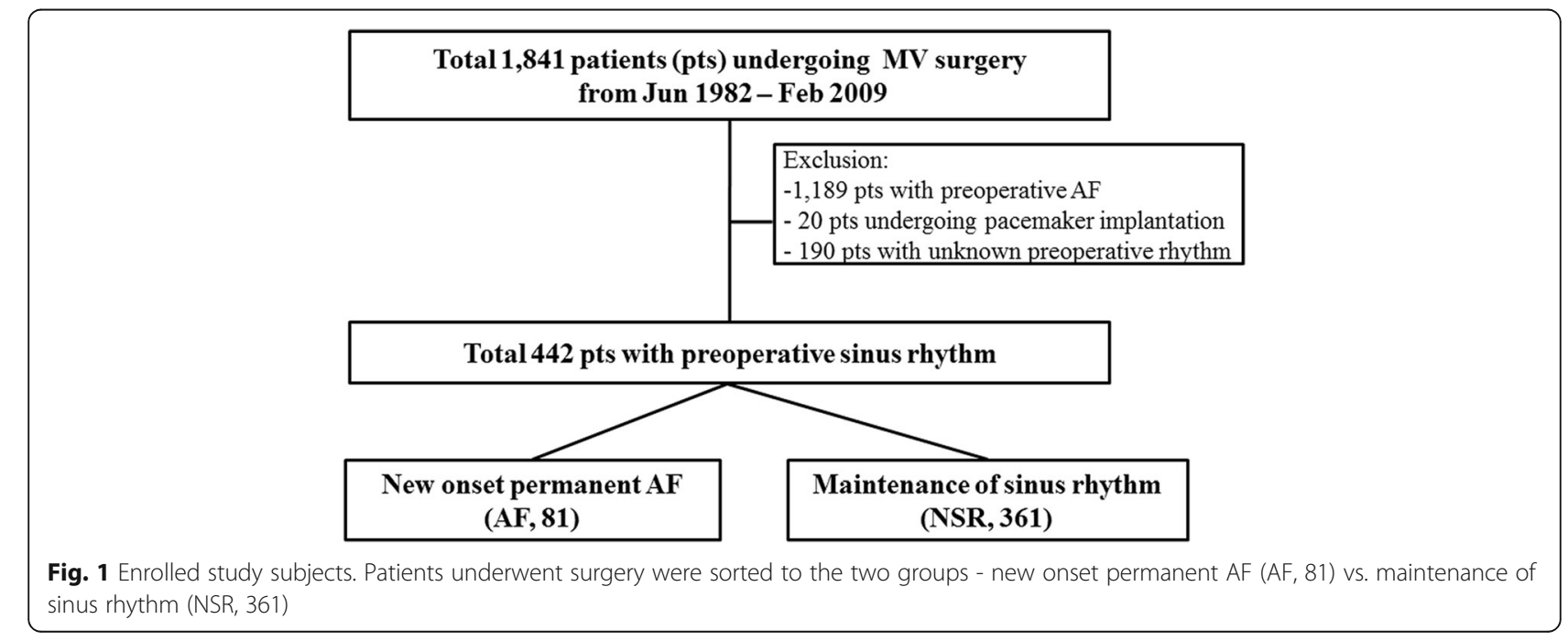


Table 1 Baseline characteristics of the patients

\begin{tabular}{|c|c|c|c|}
\hline Variables & $\operatorname{NSR}(n=361)$ & $\operatorname{AF}(n=81)$ & $p$ \\
\hline Age at surgery (years) & $41 \pm 13$ & $41 \pm 11$ & 0.782 \\
\hline Male gender & $151(42 \%)$ & $39(49 \%)$ & 0.264 \\
\hline Body surface area $\left(\mathrm{m}^{2}\right)$ & $1.65 \pm 0.16$ & $1.64 \pm 0.16$ & 0.967 \\
\hline Etiology & & & 0.018 \\
\hline Rheumatic etiology & $284(79 \%)$ & $73(90 \%)$ & \\
\hline Non-rheumatic valvular disease & $77(21 \%)$ & $8(10 \%)$ & \\
\hline Diagnosis & & & 0.065 \\
\hline Pure mitral regurgitation & $205(57 \%)$ & $37(46 \%)$ & \\
\hline Presence of mitral stenosis & $156(43 \%)$ & $44(54 \%)$ & \\
\hline Combined with other valve & $180(58 \%)$ & $44(70 \%)$ & 0.091 \\
\hline Type of surgery & & & 0.478 \\
\hline Mitral valve replacement & $348(96.4 \%)$ & 79 (97.5\%) & \\
\hline Bioprosthesis & $7(2.0 \%)$ & $2(2.5 \%)$ & \\
\hline Mechanical & $341(98.0 \%)$ & 77 (97.5\%) & \\
\hline Mitral valve repair & $13(3.6 \%)$ & $2(2.5 \%)$ & \\
\hline Annular size & $28.4 \pm 2.1$ & $29.0 \pm 2.6$ & 0.070 \\
\hline Preoperative heart rate (bpm) & $76 \pm 19$ & $75 \pm 15$ & 0.762 \\
\hline \multicolumn{4}{|l|}{ Preoperative blood pressure $(\mathrm{mmHg})$} \\
\hline Systolic blood pressure & $121 \pm 17$ & $123 \pm 16$ & 0.825 \\
\hline Diastolic blood pressure & $75 \pm 13$ & $74 \pm 10$ & 0.623 \\
\hline Postoperative HR & $73 \pm 18$ & $72 \pm 14$ & 0.854 \\
\hline \multicolumn{4}{|l|}{ Postoperative blood pressure } \\
\hline Systolic blood pressure & $119 \pm 15$ & $120 \pm 15$ & 0.718 \\
\hline Diastolic blood pressure & $73 \pm 11$ & $74 \pm 11$ & 0.777 \\
\hline
\end{tabular}

with new onset permanent $\mathrm{AF}(p=0.018)$. The median interval from the surgery to the occurrence of AF was 9.2 years (110.6 \pm 78.9 months), and the mean follow-up duration was not significantly different in both groups (9.8 \pm 5.9 years in the NSR vs. $9.4 \pm 6.5$ years in the AF, $p=0.566)$. The TTE parameters before and after surgery are listed in Table 2. Pre- and post-operative LV EF were significantly lower in the AF group $(63 \pm 10 \%$ in the NSR vs. $59 \pm 14 \%$ in the AF, $p=0.026 \& 61 \pm 10 \%$ in the NSR vs. $57 \pm 14 \%$ in the AF, $p=0.006$ ), although the LV EF of both groups were in normal range. Pre-operative LA AP dimension $(51 \pm 9 \mathrm{~mm}$ in the NSR vs. $53 \pm 7 \mathrm{~mm}$ in the AF, $p=0.080)$ and LAVI $\left(58 \pm 25 \mathrm{ml} / \mathrm{m}^{2}\right.$ in the NSR vs. $63 \pm 23 \mathrm{ml} / \mathrm{m}^{2}$ in the AF, $\left.p=0.399\right)$ were not significantly different in both groups. However, the degree of reduction of LAVI $\left(21 \pm 21 \mathrm{ml} / \mathrm{m}^{2}\right.$ in the NSR vs. $11 \pm$ $23 \mathrm{ml} / \mathrm{m}^{2}$ in the AF, $\left.p=0.041\right)$ and percentage reduction of LAVI $(28 \pm 28 \%$ in the NSR vs. $10 \pm 37 \%$ in the AF, $p<.001)$ were significantly smaller in the AF group (Fig. 2). Therefore, post-operative LA size was significantly larger in the AF group, shown as AP dimension ( $43 \pm 6 \mathrm{~mm}$ in the NSR vs. $51 \pm 8 \mathrm{~mm}$ in the AF, $p<.001$ ) and LAVI $\left(38 \pm 13 \mathrm{ml} / \mathrm{m}^{2}\right.$ in the NSR vs. $52 \pm 16 \mathrm{ml} / \mathrm{m}^{2}$ in
Table 2 Echocardiographic parameters before and after surgery

\begin{tabular}{|c|c|c|c|}
\hline & $\operatorname{NSR}(n=361)$ & AF $(n=81)$ & $p$ \\
\hline \multicolumn{4}{|l|}{ Before surgery } \\
\hline LV end diastolic dimension ( $\mathrm{mm}$ ) & $56.6 \pm 10.8$ & $55.0 \pm 10.9$ & 0.375 \\
\hline LV end systolic dimension (mm) & $38.4 \pm 9.2$ & $38.7 \pm 9.9$ & 0.863 \\
\hline LV ejection fraction (\%) & $62.7 \pm 10.0$ & $58.9 \pm 14.1$ & 0.026 \\
\hline $\begin{array}{l}\text { LA antero-posterior dimension } \\
\text { (AP) }(\mathrm{mm})\end{array}$ & $50.7 \pm 8.7$ & $53.1 \pm 6.9$ & 0.080 \\
\hline $\begin{array}{l}\text { LA medio-lateral dimension } \\
(\mathrm{ML})(\mathrm{mm})\end{array}$ & $56.2 \pm 10.6$ & $58.6 \pm 9.9$ & 0.339 \\
\hline $\begin{array}{l}\text { LA supero-inferior dimension } \\
(\mathrm{SI})(\mathrm{mm})\end{array}$ & $62.4 \pm 9.7$ & $60.4 \pm 9.1$ & 0.372 \\
\hline $\mathrm{LA}$ volume index $\left(\mathrm{ml} / \mathrm{m}^{2}\right)^{\mathrm{a}}$ & $58.4 \pm 24.9$ & $62.9 \pm 22.8$ & 0.399 \\
\hline TR grade & $0.4 \pm 0.8$ & $1.2 \pm 1.1$ & 0.005 \\
\hline Estimated PAP & $39.2 \pm 17.5$ & $44.5 \pm 18.4$ & 0.252 \\
\hline \multicolumn{4}{|l|}{ After surgery } \\
\hline LV end diastolic dimension ( $\mathrm{mm}$ ) & $48.9 \pm 5.3$ & $50.1 \pm 8.9$ & 0.126 \\
\hline LV end systolic dimension (mm) & $33.8 \pm 5.8$ & $35.9 \pm 10.8$ & 0.015 \\
\hline LV ejection fraction (\%) & $60.9 \pm 9.5$ & $57.2 \pm 13.8$ & 0.006 \\
\hline LA AP dimension (mm) & $42.9 \pm 6.0$ & $50.7 \pm 8.1$ & $<.001$ \\
\hline LA ML dimension (mm) & $50.3 \pm 6.8$ & $56.3 \pm 7.5$ & $<.001$ \\
\hline LA SI dimension (mm) & $57.3 \pm 27.5$ & $61.8 \pm 8.2$ & 0.172 \\
\hline LA AP change (mm) & $7.7 \pm 8.4$ & $4.1 \pm 7.9$ & 0.011 \\
\hline LA ML change $(\mathrm{mm})$ & $6.7 \pm 10.4$ & $3.4 \pm 10.1$ & 0.197 \\
\hline LA SI change (mm) & $7.4 \pm 9.0$ & $1.3 \pm 8.3$ & 0.005 \\
\hline LA volume index $\left(\mathrm{ml} / \mathrm{m}^{2}\right)$ & $37.9 \pm 12.6$ & $52.1 \pm 15.6$ & $<.001$ \\
\hline LA volume change $\left(\mathrm{ml} / \mathrm{m}^{2}\right)$ & $20.5 \pm 21.3$ & $10.8 \pm 23.4$ & 0.041 \\
\hline LA volume change $\%$ & $28.1 \pm 27.9$ & $9.5 \pm 36.8$ & $<.001$ \\
\hline MDPG of the MV $(\mathrm{mmHg})$ & $3.5 \pm 1.4$ & $3.9 \pm 1.5$ & 0.023 \\
\hline Residual mitral regurgitation & & & 0.337 \\
\hline No & $352(97.5 \%)$ & $77(95.1 \%)$ & \\
\hline Trivial & $8(2.2 \%)$ & $3(3.7 \%)$ & \\
\hline More than grade I & $1(0.3 \%)$ & $1(1.2 \%)$ & \\
\hline TR grade & $0.3 \pm 0.6$ & $1.0 \pm 1.0$ & $<0.001$ \\
\hline Estimated PAP & $26.4 \pm 6.6$ & $29.8 \pm 7.1$ & 0.001 \\
\hline TAP or TVR & $33(7.5 \%)$ & $6(1.4 \%)$ & 0.828 \\
\hline
\end{tabular}

aA volume index was available only in 200 patients (176 of NSR, 24 of AF); NSR normal sinus rhythm, $A F$ atrial fibrillation, $L V$ left ventricular, $L A$ left atrial, MDPG mean diastolic pressure gradient, $T R$ tricuspid regurgitation, $P A P$ pulmonary artery pressure, TAP tricuspid valve repair with an annuloplasty ring, TVR tricuspid valve replacement

the AF, $p<.001)$. When the degree of reduction of LA dimension was compared according to the direction (AP, $\mathrm{ML}$ or SI), the change in SI direction was most prominent (Table 2). Regarding the hemodynamic variables, the postoperative mean diastolic pressure gradient (MDPG) of the MV was significantly higher in patients with permanent AF group $(3.5 \pm 1.4 \mathrm{mmHg}$ in the NSR vs. $3.9 \pm 1.5 \mathrm{mmHg}$ in the AF, $p=0.023)$. The grade of pre and post-operative tricuspid regurgitation (TR) were slightly higher in the AF 


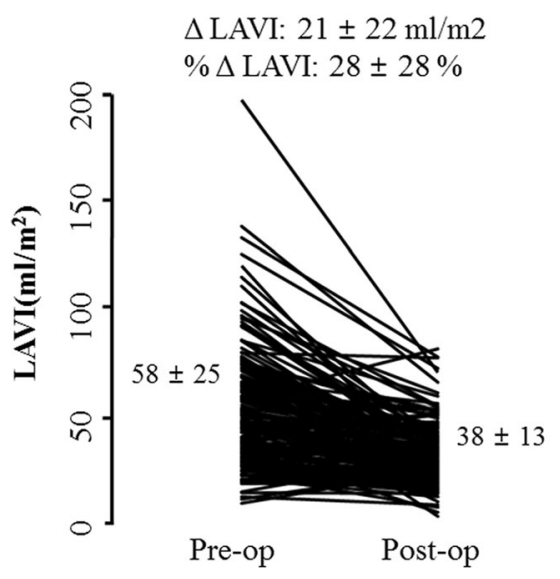

NSR $\triangle$ LAVI: $11 \pm 24 \mathrm{ml} / \mathrm{m} 2$

$\% \Delta$ LAVI: $10 \pm 36 \%$

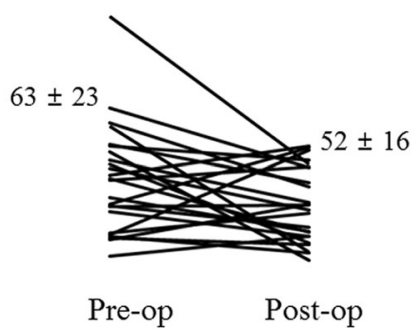

$\mathrm{AF}$

Fig. 2 Degree of left atrial reverse remodeling. LAVI, left atrial volume index; $\triangle L A V I$, change of LAVl; $\% \Delta L A V I$, percent change of LAVI, NSR, maintenance of normal sinus rhythm; $A F$, new onset permanent $A F$

group. Post-operative estimated pulmonary artery pressure (PAP) was also slightly higher in the AF group. In univariate analysis, rheumatic etiology (odds ratio $[\mathrm{OR}]=2.474,95 \%$ confidence interval $[\mathrm{CI}]=$ $1.143-5.355, p=0.021)$, lower pre $(\mathrm{OR}=0.971,95 \%$ $\mathrm{CI}=0.945-0.997, p=0.028)$ and post-operative LV EF $(\mathrm{OR}=0.970,95 \% \mathrm{CI}=0.949-0.992, p=0.007)$, higher post-operative MDPG across mitral prosthesis $(\mathrm{OR}=$ $1.212,95 \% \mathrm{CI}=1.024-1.434, p=0.025)$, lesser degree of reduction in LA size after surgery (OR $=0.790,95 \%$ $\mathrm{CI}=0.960-0.980, p<0.001)$, and large post-operative LA size $(\mathrm{OR}=1.064,95 \% \mathrm{CI}=1.045-1.083, p<0.001)$ were risk factors for the occurrence of AF. Presence of MS rather than pure MR $(\mathrm{OR}=1.767,95 \% \mathrm{CI}=0.981-$ $3.182, p=0.058$ ) was associated with the occurrence of AF with borderline significance (Table 3). Interestingly, none

Table 3 Factors determining the occurrence of atrial fibrillation after surgery (univariate analysis)

\begin{tabular}{llll}
\hline Variables & Odds ratio & $95 \%$ confidence interval & $p$ \\
\hline Rheumatic VHD & 2.474 & $1.143-5.355$ & 0.021 \\
Presence of MS & 1.767 & $0.981-3.182$ & 0.058 \\
Preoperative LV EF & 0.971 & $0.949-0.992$ & 0.028 \\
Postoperative LV EF & 0.970 & $0.949-0.992$ & 0.007 \\
$\Delta$ LAVI & 0.960 & $0.940-0.990$ & 0.007 \\
$\% \Delta$ LAVI & 0.790 & $0.960-0.980$ & $<.001$ \\
Postoperative LAVI & 1.064 & $1.045-1.083$ & $<.001$ \\
Postoperative MDPG & 1.212 & $1.024-1.434$ & 0.025 \\
Preoperative TR & 1.864 & $1.328-2.617$ & $<0.001$ \\
Postoperative TR & 2.641 & $1.922-3.630$ & $<0.001$ \\
Postoperative PAP & 1.067 & $1.025-1.110$ & 0.001 \\
\hline VHD vaVur heat dis
\end{tabular}

$V H D$ valvular heart disease, $M S$ mitral stenosis, $L V$ Left ventricular, $E F$ ejection fraction, $\triangle$ change, $L A V I$ left atrial volume index, MDPG mean diastolic pressure gradient, $T R$ tricuspid valve regurgitation, $P A P$ pulmonary artery pressrue of the parameters reflecting pre-operative LA size was associated with post-operative AF. Pre and post-operative TR $(\mathrm{OR}=1.864,95 \% \mathrm{CI}=1.328-2.617, p<0.001 \& \mathrm{OR}=$ 2.641, 95\% $\mathrm{CI}=1.922-3.630, p<0.001)$ and postoperative higher PAP $(\mathrm{OR}=1.067,95 \% \mathrm{CI}=1.025-1.110, p=0.001)$ were associated with the occurrence of AF. In multivariate analysis, post-operative LAVI was an independent predictor for the occurrence of AF (Table 4). The predictive ability of the LAVI was determined by the area under the curve of the receiver operating curve and post-operative LAVI $>39 \mathrm{ml} / \mathrm{m}^{2}$ (cut-off value) was associated with new onset permanent AF (sensitivity: 79\%, AUC: 0.762, SE: $0.051, p<0.001)$. The AF-free survival curves of patients with post-op LAVI $<39 \mathrm{ml} / \mathrm{m} 2$ or $\geq 39 \mathrm{ml} / \mathrm{m} 2$ are shown in Fig. $3(p=0.06)$.

Table 4 Factors determining the occurrence of atrial fibrillation after surgery (multivariate analysis)

\begin{tabular}{llll}
\hline Variables & Odds ratio & $\begin{array}{l}\text { 95\% confidence } \\
\text { interval }\end{array}$ & $p$ \\
\hline Rheumatic VHD & 4.683 & $0.716-30.460$ & 0.107 \\
Presence of MS & 3.534 & $0.884-14.125$ & 0.074 \\
Preoperative LV EF & 0.997 & $0.953-1.043$ & 0.815 \\
Postoperative LV EF & 1.004 & $0.957-1.054$ & 0.863 \\
$\% \Delta$ LAVI & 0.993 & $0.976-1.010$ & 0.409 \\
Postoperative LAVI & 1.098 & $1.047-1.153$ & $<.001$ \\
Postoperative MDPG of MV & 0.902 & $0.557-1.459$ & 0.673 \\
Preoperative TR & 0.686 & $0.181-2.596$ & 0.579 \\
Postoperative TR & 2.274 & $0.896-5.773$ & 0.084 \\
Postoperative PAP & 0.930 & $0.788-1.097$ & 0.389 \\
\hline
\end{tabular}

VHD valvular heart disease, $M S$ mitral stenosis, $L V$ Left ventricular, EF ejection fraction, $\triangle$ change, $L A V I$ left atrial volume index, MDPG mean diastolic pressure gradient, $M V$ mitral valve, $T R$ tricuspid valve regurgitation, PAP pulmonary artery pressrue 


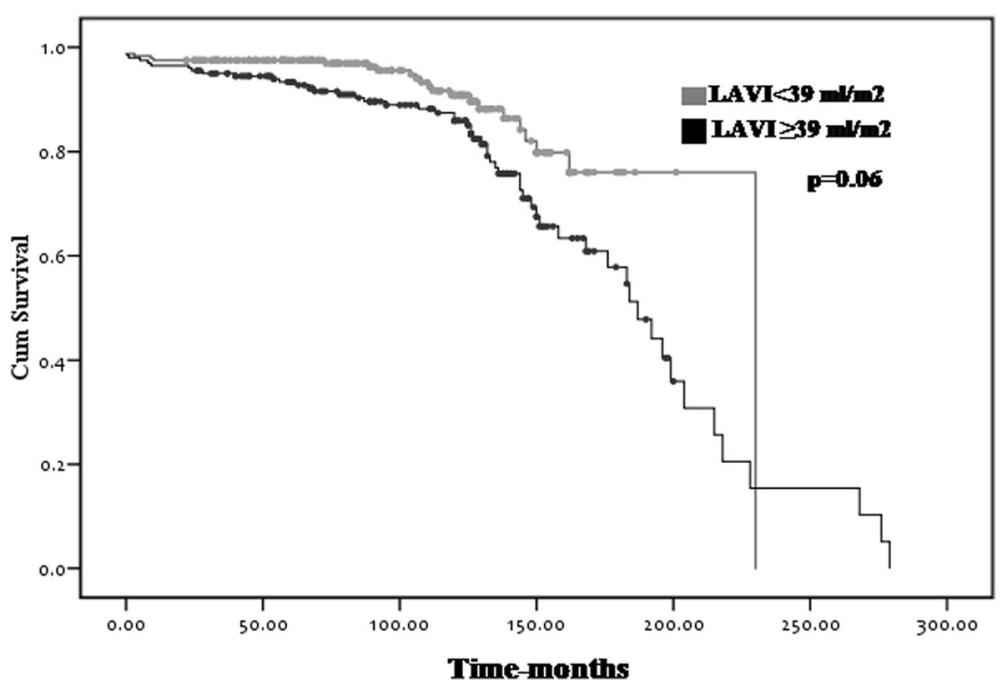

Fig. 3 AF free survival curves

\section{Discussion}

In the present study, the prevalence and predictors of new onset permanent AF after MV surgery were investigated. The results showed that new onset permanent AF is not uncommon, occurring in about $20 \%$ of patients even after successful MV surgery and pre-operative sinus rhythm. Although several parameters, such as rheumatic etiology of MV, presence of mitral stenosis (MS), lower LV EF, higher post-operative mean diastolic pressure gradient across mitral prosthesis, and lesser degree of reverse LA remodeling after surgery, were shown to be associated with the occurrence of post-operative AF, post-operative LAVI was found to be an independent predictor for the occurrence of AF in multivariate analysis. Interestingly, none of the parameters reflecting pre-operative LA size was associated with post-operative AF. These findings underscore the importance of postoperative echocardiographic assessment before dismissal of the evaluation of LV function and LA size even in patients who have undergone successful MV surgery and pre-operative sinus rhythm.

\section{Factors associated with new onset permanent AF Reverse $L A$ remodeling and post-operative $A F$}

The degree of LA reverse remodeling was different in the two groups and showed that the reduction of LAVI and decrease in percentage of LAVI were smaller in the post-op AF group. Accordingly, post-operative LA size was significantly larger in the post-op AF group. In a previous study, post-operative LAVI $\geq 60 \mathrm{ml} / \mathrm{m}^{2}$ was shown to be associated with adverse clinical outcomes in patients with organic mitral regurgitation (MR) [19]. In our study, 9 (47\%) of 19 patients who had post-operative LAVI $\geq 60 \mathrm{ml} / \mathrm{m}^{2}$ developed new onset permanent AF, whereas $15(8 \%)$ of 181 patients who had post-operative
LAVI $<60 \mathrm{ml} / \mathrm{m} 2$ had new onset AF $(p<0.001)$. These findings are consistent with previous research [20]. However, in our study, post-operative LAVI $\geq 39 \mathrm{ml} / \mathrm{m}^{2}$ was selected as a cut-off value for new onset AF. It had a sensitivity of $79 \%$ as well as the largest AUC (0.762). The smaller cut-off value of LAVI in our study was probably due to the inclusion of the patients with MS in our study. Regarding the direction of LA reverse remodeling, the change in SI dimension was the most prominent when compared with that of the AP and ML dimensions. Therefore, assessing the change in LA size only in the AP dimension may not accurately reflect the change in LA size. Thus, the degree of LA reverse remodeling could be underestimated.

\section{Impact of $L V$ systolic function on post-operative AF}

In our study, lower pre- and post-operative LV EF was also associated with new onset AF. Despite similar preoperative LAVI, lesser degrees of reduction in LAVI and decreases in percentage of LAVI occurred in patients with LV $\mathrm{EF}<60 \%$. LV systolic dysfunction usually accompanies LV diastolic dysfunction and elevated LV filling pressures. Despite similar LA size, the presence of LV systolic dysfunction and concomitant LV diastolic dysfunction with elevated LV filling pressure might interfere with LA reverse remodeling.

\section{Pre-operative etiology of MV pathology}

New onset permanent AF occurred more frequently in patients with rheumatic etiology and presence of MS rather than pure MR. Because LA kinetic energy is different in MS and MR, a long-standing pressure overload of the LA in MS might be associated with higher LA kinetic energy than volume overload in MR. Therefore, increased LA work in MS may result in further LA 
fatigue and failure over time, which may disturb LA reverse remodeling $[2,21]$.

Role of post-operative echocardiography before dismissal Although successful intervention was performed on diseased MV, AF can occur in patients with post-operative LAVI $\geq 39 \mathrm{ml} / \mathrm{m}^{2}$ according to the results from our study. Therefore, it is imperative to not only focus on the successful results of valve surgery but also perform postoperative echocardiography to evaluate post-operative LAVI to predict the occurrence of AF.

Echocardiography has a different role in the evaluation of valvular heart disease (VHD) at different stages before and after surgery. Pre-operative TTE should provide an accurate diagnosis to determine the possible cause of valvular diseases $[22,23]$. In addition, quantitative echocardiographic evaluation of LV size and function is a key factor in clinical decision making in adults with VHD [24-27]. Other key echocardiographic data includes LV diastolic function, LA enlargement, and the presence of intra-cardiac thrombus, pulmonary artery pressures, and so on [28]. Despite the important information obtained from pre-operative echocardiography, none of the preoperative echocardiographic parameters provides predictive information regarding post-operative permanent AF in this study. Intra-operatively, transesophageal echocardiography (TEE) provides a roadmap for the surgeons regarding the location and severity of $\mathrm{MV}$ pathologic lesions, enhancing the ability to detect unexpected associated lesions. In addition, intra-operative TEE is used to confirm results of surgical procedures on the MV, which can result in improved surgical outcomes [28, 29]. Therefore, the American College of Cardiology and the American Heart Association have established guidelines for the management of patients with VHD, which state that the use of intra-operative TEE in MV repair is a class I indication [30].

Although the importance of pre-operative and intraoperative echocardiographic evaluations of MV disease has been well recognized, the role of post-operative predischarge TTE has been overlooked in patients undergoing MV surgery. Unlike pre-operative echocardiographic parameters, post-operative LAVI measured before dismissal was able to predict the occurrence of post-operative permanent AF in patients undergoing MV surgery. Based on these results, the importance of post-operative echocardiographic assessment is emphasized not only for assessing the results of MV surgery but also for evaluating cardiac chamber size and function, particularly LA volume.

\section{Limitations}

The current study has several limitations. First, it was a retrospective study, so the data collection was done by reviewing medical charts and recorded echocardiographic data. Therefore, the measurement of LAVI was available in only 200 of 442 patients, and only echocardiographic report was available in the remainder. And, the majority of the study patients had undergone MVR rather than MV repair. Anticoagulation is one of the most important treatments for AF. However, all patients should have life-long anticoagulation therapy for the implanted valve, except for MV reconstructions and bioprosthetic valve implantation. Therefore, our results cannot apply to patients who have undergone MV repair.

\section{Conclusions}

Newly developed postoperative permanent AF is not uncommon, occurring in $18 \%$ of patients who have undergone successful MV surgery despite pre-operative sinus rhythm. Rheumatic etiology, the presence of MS, lower LV EF, lesser degree of LA reverse remodeling, and larger post-operative LAVI were associated with new onset permanent AF. Post-operative LAVI > $39 \mathrm{ml} / \mathrm{m} 2$ was an independent predictor for the occurrence of AF.

\section{Abbreviations}

AF: atrial fibrillation; AP: anteroposterior; Cl: confidence interval; ECG: electrocardiogram; EF: ejection fraction; LA: left atrial; LAVI: left atrial volume index; LV: left ventricular; MDPG: mean diastolic pressure gradient; ML: mediolateral; MR: mitral regurgitation; MS: mitral stenosis; MV: mitral valve; NSR: normal sinus rhythm; OR: odds ratio; ROC: receiver-operatingcharacteristic; SD: standard deviation; SI: superior/inferior;

TEE: transesophageal echocardiography; TTE: transthoracic echocardiography; VHD: valvular heart disease

\section{Acknowledgements}

There is nothing to declare with this study.

\section{Funding}

This research received no specific grant from any funding agency.

\section{Availability of data and materials}

The whole images or part of it, neither has been published and is not being considered for publication elsewhere in whole or part in any language.

\section{Author's contributions}

MKK and JWH designed this study as the first author and corresponding author. BYJ confirmed ECG. CYS, IJC, WIY, and JM made the SPSS data together. YJ, NC, and BCC were involved in data acquisition and analysis in this study. All authors read and approved the final manuscript.

Consent for publication

Not applicable.

\section{Ethics approval and consent to participate}

All procedures performed in studies involving human participants were in accordance with the ethical standards of the institutional and/or national research committee and with the 1964 Helsinki declaration and its later amendments or comparable ethical standards.

Competing interests

There are no conflicts of interest in this study.

\section{Publisher's Note}

Springer Nature remains neutral with regard to jurisdictional claims in published maps and institutional affiliations. 


\section{Author details}

'Division of Cardiology, Kangnam Sacred Heart Hospital, Hallym University Medical Center, Seoul, South Korea. ${ }^{2}$ Division of Cardiology and Cardiovascular Surgery, Severance Cardiovascular Hospital, Yonsei University College of Medicine, 134 Shinchon-dong, Seodaemun-gu, Seoul 120-752, Republic of Korea. ${ }^{3}$ Division of Cardiology, CHA Bundang Medical Center, CHA University, Seongnam, South Korea. ${ }^{4}$ Division of Cardiology and Cardiovascular Surgery, Department of Internal Medicine, Gachon University of Medicine and Science, Incheon, South Korea.

Received: 20 December 2017 Accepted: 28 February 2018 Published online: 09 March 2018

\section{References}

1. Henry WL, Morganroth J, Pearlman AS, Clark CE, Redwood DR, Itscoitz SB, et al. Relation between echocardiographically determined left atrial size and atrial fibrillation. Circulation. 1976;53:273-9.

2. Cho DK, Ha JW, Chang BC, Lee SH, Yoon SJ, Shim CY, et al. Factors determining early left atrial reverse remodeling after mitral valve surgery. Am J Cardiol. 2008:101:374-7.

3. Tsang TS, Abhayaratna WP, Barnes ME, Miyasaka Y, Gersh BJ, Bailey KR, et al. Prediction of cardiovascular outcomes with left atrial size: is volume superior to area or diameter? J Am Coll Cardiol. 2006;47:1018-23.

4. Abhayaratna WP, Seward JB, Appleton CP, Douglas PS, Oh JK, Tajik AJ, et al. Left atrial size: physiologic determinants and clinical applications. J Am Coll Cardiol. 2006:47:2357-63.

5. John B, Stiles MK, Kuklik P, Brooks AG, Chandy ST, Kalman JM, et al. Reverse remodeling of the atria after treatment of chronic stretch in humans: implications for the atrial fibrillation substrate. J Am Coll Cardiol. 2010;55: 1217-26.

6. Guffi M, Visconti Brick A, Seixas T, Portilho C, Klier Peres A, Vieira JJ Jr, et al. Intraoperative treatment of chronic atrial fibrillation with ultrasound. J Cardiovasc Surg. 2005;46:69-75.

7. Maisel WH, Rawn JD, Stevenson WG. Atrial fibrillation after cardiac surgery Ann Intern Med. 2001;18(135):1061-73.

8. Mathew JP, Fontes ML, Tudor IC, Ramsay J, Duke P, Mazer CD, et al. Investigators of the Ischemia Research and Education Foundation; multicenter study of perioperative ischemia research group. A multicenter risk index for atrial fibrillation after cardiac surgery JAMA. 2004;291:1720-9.

9. Angelini P, Feldman MI, Lufschanowski R, Leachman RD. Cardiac arrhythmias during and after heart surgery: diagnosis and management. Prog Cardiovasc Dis. 1974;16:469-95.

10. Tchervenkov Cl, Wynands JE, Symes JF, Malcolm ID, Dobell AR, JEI M. Persistent atrial activity during cardioplegic arrest: a possible factor in the etiology of post-operative supraventricular tachyarrhythmias. Ann Thorac Surg. 1983:36:437-43.

11. Chen $X$, Newman M, Rosenfeldt FL. Internal cardiac cooling improves atrial preservation: electrophysiological and biochemical assessment. Ann Thorac Surg. 1988;46:406-11.

12. Smith PK, Buhrman WC, Levett JM, Ferguson TB Jr, Holman WL, Cox JL. Supraventricular conduction abnormalities following cardiac operations: a complication of inadequate atrial preservation. J Thorac Cardiovasc Surg. 1983:85:105-15.

13. White HD, Antman EM, Glynn MA, Collins JJ, Cohn LH, Shemin RJ, et al. Efficacy and safety of timolol for prevention of supraventricular tachyarrhythmias after coronary artery bypass surgery. Circulation. 1984;70: 479-84.

14. Kalman JM, Munawar M, Howes LG, Louis WJ, Buxton BF, Gutteridge G, et al. Atrial fibrillation after coronary artery bypass grafting is associated with sympathetic activation. Ann Thorac Surg. 1995;60:1709-15.

15. Klemperer JD, Klein IL, Ojamaa K, Helm RE, Gomez M, Isom OW, et al. Triiodothyronine therapy lowers the incidence of atrial fibrillation after cardiac operations. Ann Thorac Surg. 1996;61:1323-9.

16. Dunning J, Treasure T, Versteegh M, Nashef SA, Audit EACTS, Committee G. Guidelines on the prevention and management of de novo atrial fibrillation after cardiac and thoracic surgery. Eur J Cardiothorac Surg. 2006;30:852-72.

17. Kinoshita T, Asai T, Nishimura O, Hiramatsu N, Suzuki T, Kambara A, et al. Statin for prevention of atrial fibrillation after off-pump coronary artery bypass grafting in Japanese patients. Circ J. 2010;74:1866-72.

18. Lang RM, Bierig M, Devereux RB, Flachskampf FA, Foster E, Pellikka PA, et al. Chamber quantification writing group; American Society of
Echocardiography's guidelines and standards committee; European Association of Echocardiography. Recommendations for chamber quantification: a report from the American Society of Echocardiography's guidelines and standards committee and the chamber quantification writing group, developed in conjunction with the European Association of Echocardiography, a branch of the European Society of Cardiology. J Am Soc Echocardiogr. 2005;18:1440-63.

19. American College of Cardiology/American Heart Association Task Force on Practice Guidelines; Society of Cardiovascular Anesthesiologists; Society for Cardiovascular Angiography and Interventions; Society of Thoracic Surgeons, Bonow RO, Carabello BA, Kanu C, de Leon AC Jr, Faxon DP, et al. ACC/AHA 2006 guidelines for the management of patients with valvular heart disease: a report of the American College of Cardiology/American Heart Association task force on practice guidelines (writing committee to revise the 1998 guidelines for the Management of Patients with Valvular Heart Disease): developed in collaboration with the Society of Cardiovascular Anesthesiologists: endorsed by the Society for Cardiovascular Angiography and Interventions and the Society of Thoracic Surgeons. Circulation. 2006:115:e84-231.

20. Le Tourneau T, Messika-Zeitoun D, Russo A, Detaint D, Topilsky Y, Mahoney DW, et al. Impact of left atrial volume on clinical outcome in organic mitral regurgitation. J Am Coll Cardiol. 2010:56:570-8.

21. Boudoulas $H$, Boudoulas D, Sparks EA, Pearson AC, Nagaraja HN, Wooley CF. Left atrial performance indices in chronic mitral valve disease. J Heart Valve Dis. 1995;4Suppl(2):S242-7.

22. Vahanian A, Baumgartner $H$, Bax J, Butchart E, Dion R, Filippatos $G$, et al. Task force on the Management of Valvular Hearth Disease of the European Society of Cardiology; ESC Committee for practice guidelines. Guidelines on the management of valvular heart disease: the task force on the management of Valvular heart disease of the European Society of Cardiology. Eur Heart J. 2007;28:230-68.

23. American College of Cardiology; American Heart Association Task Force on Practice Guidelines (Writing Committee to revise the 1998 guidelines for the management of patients with valvular heart disease); Society of Cardiovascular Anesthesiologists, Bonow RO, Carabello BA, Chatteriee K, et al. ACC/AHA 2006 guidelines for the management of patients with valvular heart disease: a report of the American College of Cardiology/American Heart Association task force on practice guidelines (writing committee to revise the 1998 guidelines for the management of patients with valvular heart disease) developed in collaboration with the Society of Cardiovascular Anesthesiologists endorsed by the Society for Cardiovascular Angiography and Interventions and the Society of Thoracic Surgeons. J Am Coll Cardiol. 2006;48:e1-148.

24. Rosenhek R, Rader F, Klaar U, Gabriel H, Krejc M, Kalbeck D, et al. Outcome of watchful waiting in asymptomatic severe mitral regurgitation. Circulation. 2006:113:2238-44

25. Enriquez-Sarano M, Avierinos JF, Messika-Zeitoun D, Detaint D, Capps M, Nkomo V, et al. Quantitative determinants of the outcome of asymptomatic mitral regurgitation. N Engl J Med. 2005;352:875-83.

26. Grigioni F, Tribouilloy C, Avierinos JF, Barbieri A, Ferlito M, Trojette F, et al. MIDA investigators. Outcomes in mitral regurgitation due to flail leaflets a multicenter European study. JACC Cardiovasc Imaging. 2008;1:133-41.

27. Enriquez-Sarano M, Sundt TM 3rd. Early surgery is recommended for mitral regurgitation. Circulation. 2010;121:804-11.

28. Otto CM, Bonow RO, et al. Valvular heart disease. Third edition. 431-436.

29. Miller D, Farah MG, Liner A, Fox K, Schlucher M, Hoit BD. The relation between quantitative right ventricular ejection fraction and indices of tricuspid annular motion and myocardial performance. J Am Soc Echocardiogr. 2004:17:443-7.

30. Bonow RO, KC CBAC, de Leon AC Jr, Faxon DP, Freed MD, et al. ACC/AHA 2006 guideline for the management of patients with valvular heart disease: a report of the American college of cardiology/American heart association task force on practice guidelines (writing committee to revise the 1998 guidelines for the management of patients with Valvular heart disease): developed in collaboration with the Society of Cardiovascular Anestheiologists: endorsed by the Society for Cardiovascular Angiography and Intervention and the Society of Thoracic Surgeons. Circulation. 2006; 114:e84-231. 